\title{
CT-guided Lung Fine Needle Aspiration Biopsy: Analysis of Efficacy, Yield and Intricacies
}

\begin{abstract}
Aim: This study aims to evaluate various factors that affect the cytological yield while performing computed tomography (CT) guided lung fine needle aspiration biopsy and to determine the complication rate of this procedure. Materials and Methods: In this cross sectional study, we analyzed 70 patients undergoing CT-guided transthoracic lung fine-needle aspiration biopsy (FNAB). 22 -gauge spinal needle was used in sixty patients and 20-gauge in ten patients. The presence and absence of an onsite cytopathologist affecting the adequacy of yield for a conclusive cytodiagnosis was compared in groups of 35 patients each. The incidence of complications such as pneumothorax, pulmonary hemorrhage was recorded. Results: Cytological yield was adequate for a conclusive cytodiagnosis in 59 cases $(84.2 \%)$. Thirty-seven cases $(52.8 \%)$ were malignant with adenocarcinoma $(70.2 \%)$ being the most common, 22 cases $(31.4 \%)$ had benign etiology. Cytological yield was adequate for a conclusive diagnosis in the group $(n=35)$ with an onsite cytopathologist $(100 \%)$ compared with those cases without an onsite cytopathologist $(68.6 \%)(P=0.005)$. Pneumothorax was observed in 16 cases $(22.8 \%)$, the incidence of pneumothorax was higher when there was an intervening parenchyma $(P=0.005)$. Conclusion: CT-guided transthoracic FNAB is an accurate method to rule out malignancy with a reasonable rate of complications. The presence of an onsite-cytopathologist significantly improves the adequacy of yield for a conclusive cytodiagnosis, and should be routinely employed. Pneumothorax and pulmonary hemorrhage are the most common complications as a result of FNAB. The incidence of pneumothorax is higher when there is intervening lung parenchyma.
\end{abstract}

Keywords: Computed tomography, cytopathologist, fine-needle aspiration biopsy, lung cancer

\section{Introduction}

The lung together with the bronchi account for highest incidence rate of invasive cancer in males and females, as per WHO estimates. Accurate cytological diagnosis of pulmonary lesion is vital for detecting lung cancer. Percutaneous computed tomography (CT)-guided lung biopsy has a high reported accuracy for obtaining a cytological diagnosis. ${ }^{[1,2]}$ Many investigators have observed that the diagnosis of CT-guided biopsy of chest lesion depends on numerous variables such as location of lesion, lung capacity (forced expiratory volume in one second/forced vital capacity), depth of lesion, size of lesion, needle size, technique and type of biopsy device, number of passes, and presence of an onsite cytopathologist. The most common complication of percutaneous lung biopsy is pneumothorax, which has been reported to occur between $9 \%$ and $44 \%$ of the patients. ${ }^{[3-7]}$

This is an open access article distributed under the terms of the Creative Commons Attribution-NonCommercial-ShareAlike 3.0 License, which allows others to remix, tweak, and build upon the work non-commercially, as long as the author is credited and the new creations are licensed under the identical terms.

For reprints contact: reprints@medknow.com
Reported risk factors for pneumothorax are lesion depth, angle of needle path, and the number of needle passes. A short depth and a needle path that is near perpendicular to the pleura have been associated with reduced incidence of pneumothorax. ${ }^{[8]}$ Other reported complications are hemoptysis, intrapulmonary hemorrhage with an increased risk of bleeding in lesions of depth more than $2 \mathrm{~cm},{ }^{[9]}$ pulmonary venous air embolism leading to air within the intracerebral or coronary circulation, hemothorax and rarely implantation of malignant cells along the needle tract. ${ }^{[10]}$

Fine-needle aspiration biopsy (FNAB) has an accuracy of up to $95 \%$ for malignant lesions ${ }^{[11]}$ but the yield for benign lesions is only $(10 \%-50 \%){ }^{[12-14]}$ Cytology is reported to be less reliable than histology in determining the cell type in malignant lesions. There is wide variation in reported diagnostic accuracies of FNAB between

\footnotetext{
How to cite this article: Nair AV, Anirudh $\mathrm{S}$, Moorthy S, Cyril P, Rajamma BM, Ramachandran PV. CT-guided lung fine needle aspiration biopsy: Analysis of efficacy, yield and intricacies. Indian J Med Paediatr Oncol 2018;39:178-83.
}

\section{Anirudh V Nair, Soumya Anirudh', Srikanth Moorthy', P Cyril2, Bindhu Mangalath Rajamma ${ }^{3}$, PV Ramachandran ${ }^{2}$}

Department of Radiodiagnosis, Kerala Institute of Medical Science, ${ }^{\prime}$ Department of Pathology, Government Medical College Hospital, Trivandrum, Departments of ${ }^{2}$ Radiodiagnosis and ${ }^{3}$ Pathology, Amrita Institute of Medical Science, Kochi, Kerala, India
Address for correspondence: Dr. Anirudh V Nair, Department of Radiodiagnosis, Kerala Institute of Medical Science, Trivandrum, Kerala, India.

E-mail:dranirudhnair@gmail. com

\section{Access this article online}

Website: www.ijmpo.org

DOI: 10.4103/ijmpo.ijmpo_86_17 Quick Response Code:

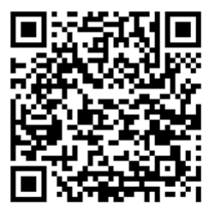


different institutions, ranging from $64 \%$ to $97 \% \cdot{ }^{[15,16]}$ A high diagnostic accuracy is best achieved with large nodules. ${ }^{[15-18]}$

\section{Materials and Methods}

The study was carried out in the Department of Radiodiagnosis and Interventional radiology, from July 2011 to December 2013. Seventy patients were included in the study. The Ethics Committee of the institution approved this prospective cross-sectional study. Informed consent was taken from all the patients undergoing study. Based on the results available from existing literature on the percentage of positivity, in the presence and absence of an onsite cytopathologist ${ }^{[19]}$ and with $95 \%$ confidence and $80 \%$ power minimum sample size comes to 35 in each group.

Our inclusion criteria included patient population of any age or sex with a suspicious lung lesion for a cytological confirmation through CT-guided chest FNAB of; (1) A solitary nodule, or a nodule which is not amenable to biopsy by bronchoscopy; (2) Multiple nodules suspicious of malignancy; (3) Persistent infiltrates (single/multiple) but no diagnosis on sputum culture, serology, bronchoalveolar lavage; (4) Hilar mass and a negative bronchoscopy. We excluded partially treated patients or those post-radiation or post-chemotherapy patients requiring FNAB.

Pre-procedure investigations including complete blood count, prothrombin time international normalized ratio, virology, etc. were done. Plain and contrast enhanced CT chest was done if not availed before the procedure. FNAB was done on an OP basis after obtaining informed consent. On the table, a multi detector CT scanners 64 or 16 slice (Siemens) patient was positioned on the CT table in a prone, supine, or decubitus position as appropriate [Figure 1]. A CT scan of the thorax was performed. If an adequate CT is available, then a limited CT of thorax was taken. A needle path that shall avoid ribs and vascular structures was selected. Each needle path was chosen so as to have the shortest possible depth and the most perpendicular

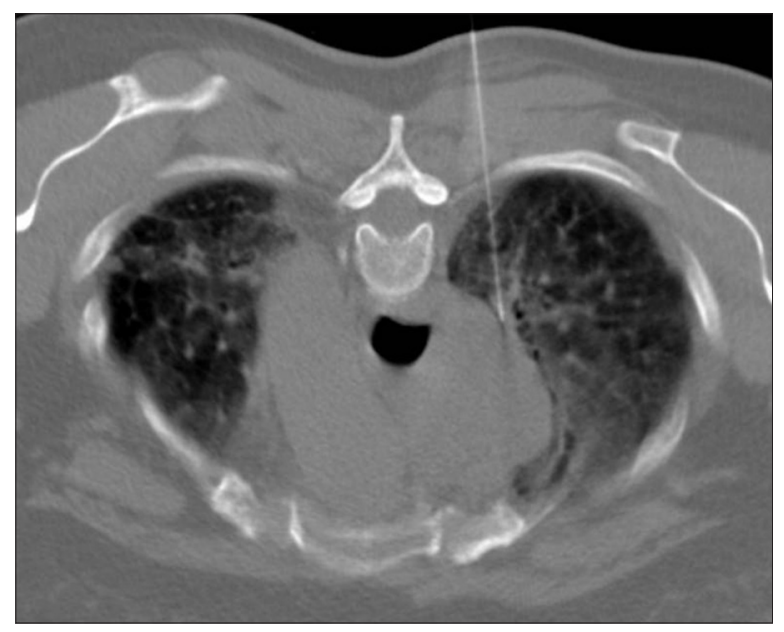

Figure 1: A 59-year-old female, mediastinal lesion under evaluation. Patient placed in prone position, posterior approach angle to the pleura. The skin entry site was marked using a laser grid system. The entry site cleaned and prepped in the usual sterile fashion. Local anesthesia administered using $2 \%$ lidocaine. A $20 \mathrm{~F}$ or 22 FNAB needle advanced under CT guidance to the edge of the lesion. Breath holding technique was employed while crossing the pleura. The sample was then sent to the cytologist for evaluation. An onsite pathologist was present in a group of patients. Repeat passes performed as needed.

A positive cytology result is considered for any cytology that is definitively diagnostic (e.g., squamous carcinoma or adenocarcinoma) or a report that is suggestive or suspicious of a diagnosis (e.g., highly suspicious, atypical, and not able to exclude carcinoma). A negative cytology is one which turned out to be paucicellular or inadequate sample. Post procedure chest radiograph was performed in all patients 1 hour after the FNAB. Small pneumothoraces was managed conservatively with monitoring of vital signs and follow up chest $\mathrm{X}$ rays.

Pneumothoraces that is causing respiratory distress was planned to be managed by placement of a pleural catheter and admission to an inpatient service. Diagnosis was confirmed with a post-surgery histopathology report or a repeat core needle biopsy after FNAB or the FNAB report itself.

\section{Results}

Seventy patients with suspicious thoracic mass lesions detected on chest X-ray or CT chest were included in this study. There were 51 (73\%) males and 19 (27\%) females in the age group 17-82 years [mean age 61; Table 1].

The size of the lesion for which FNAB was done varied from 1.4 to $14 \mathrm{~cm}$ (mean size of $4.57 \mathrm{~cm}$ ). Cytological yield was adequate for a conclusive cytodiagnosis in 59 cases (84.2\%). Thirty-seven cases $(52.8 \%)$ were malignant, 22 cases $(31.4 \%)$ had benign etiology; cytodiagnosis was inconclusive in 11 cases $(15.7 \%)$ [Table 2]. The inconclusive results were due to scanty aspirate as well as scanty cellularity with which no impression could be formed by the pathologist.

Adenocarcinoma was the most common (70.2\%) of malignant histopathological pattern [Table 3]. We found that the cytological yield was adequate for a

Table 1: Pie chart showing study population

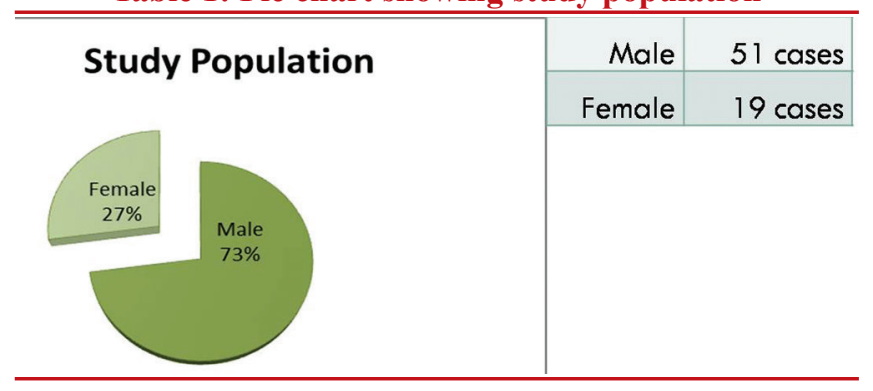


conclusive diagnosis in the group $(n=35)$ with an onsite cytopathologist $(100 \%)$, versus with those cases without an onsite cytopathologist $(68.6 \%)$ [Table 4$]$.

Out of 10, 9 cases (90\%) have adequate cytological yield for cytodiagnosis with a 20-gauge needle, while 50 out of 60 cases $(83.3 \%)$ had adequate cytological yield for cytodiagnosis with a 22-gauge needle. There was no significant statistical correlation between the size of needle and the cytological yield, as well as size of needle with the incidence of complications.

The number of passes increased with decrease in size of lesion. However, there was no significant statistical correlation [Tables 5 and 6].

\section{Table 2: Graphical representation of cytological yield}

\section{Cytological yield}

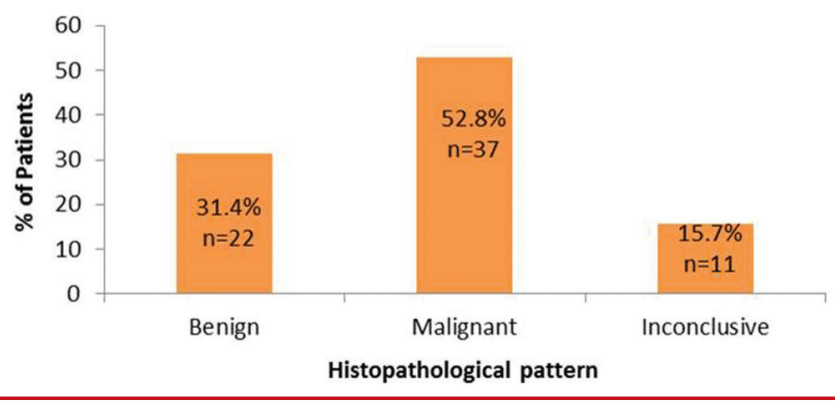

Table 3: Pie chart showing cytological diagnosis

Cytological diagnosis

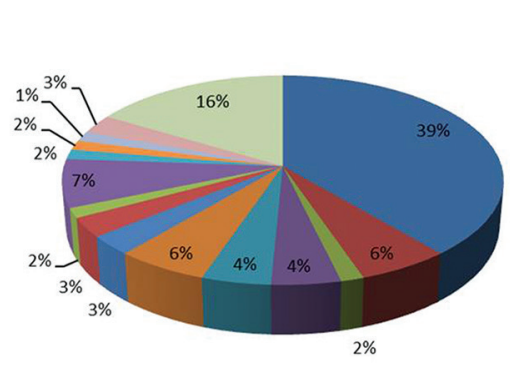

adenocarcinoma - Squamous cell carcinoma - Small cell carcinoma - Poorly differentiated neoplasm I Highly suspicious Benign inflammatory a Fungal

- Benign teratoma

al Chondroid hamartoma

- Granulomatous inflammatory

m Thymoma

III Lipom

Benign bronchial neoplasm

- No malignancy

No conclusion possible

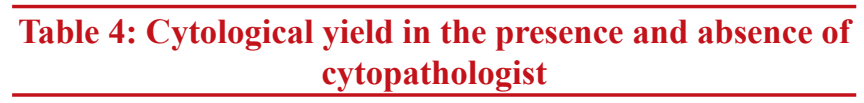

\section{Cytological yield}

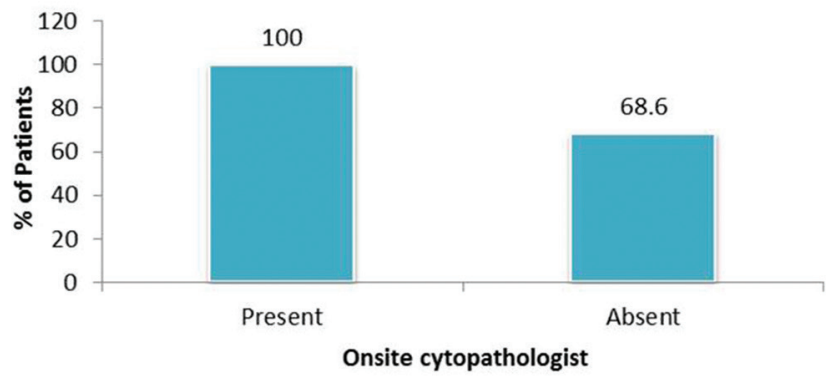

The complications we encountered were pain at the puncture site, pneumothorax, and pulmonary hemorrhage. Pneumothorax was observed in 16 cases (22.8\%), the incidence of pneumothorax was higher when there was an intervening parenchyma (13 cases; $81.2 \%$ ) [Table 7]. The total number of passes varied from 1 to maximum of 4 . The incidence of pneumothorax was higher when two or more passes were made [Tables 8 and 9]. Pulmonary hemorrhage was seen in 16 cases $(22.8 \%)$. Small amount of pulmonary hemorrhage was seen around the lesion or along the needle track which required no treatment.

\section{Discussion}

With an increasing need for histopathological characterization of lung pathology, and with advent
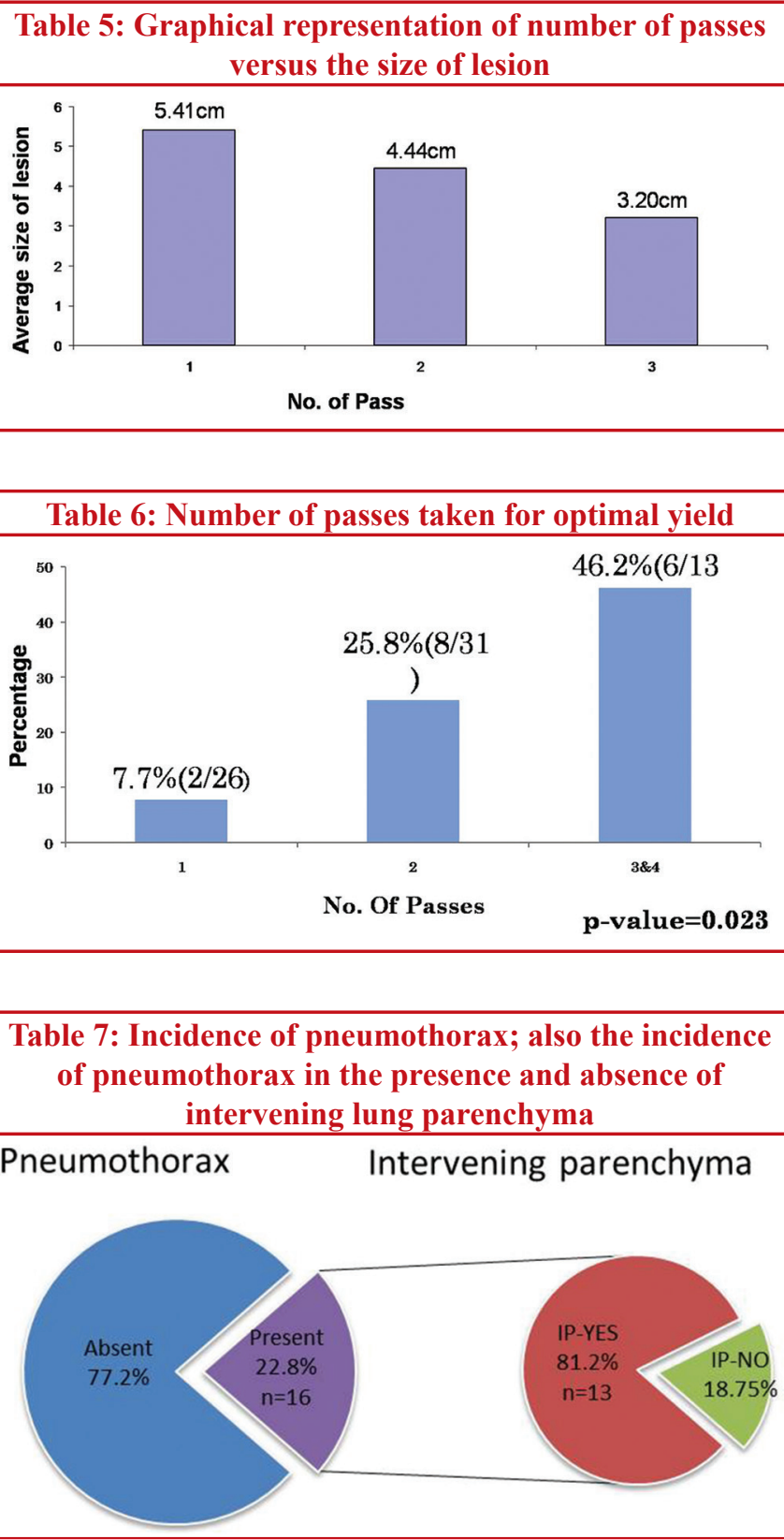
of evolving technologies such as needle technology, multiplanar imaging, and immunohistochemistry. CT-guided FNAB has evolved to be an accurate and safe method for obtaining tissue sample for histopathological characterization of pulmonary or mediastinal lesion. The main objective of guided FNAB is to rule out an underlying malignancy although it can be used for definitive diagnosis of some benign neoplasms and infections such as tuberculosis. ${ }^{[20]}$

The reported accuracy of FNAB in the literature ranged from $64 \%$ to $97 \%{ }^{[21]}$ In this study, the diagnostic accuracy of CT-guided lung FNAB was $80 \%$.

Immediate assessment for cytological yield by an onsite cytopathologist with further passes made when necessary had been shown by previous studies to improve the adequacy of cytological yield..$^{[22-24]}$ In this study, the cytological yield and adequacy rose significantly in the group of patients in the presence of an onsite cytopathologist. There was no significant correlation in the presence of cytopathologist affecting other factors such as number of passes or complications.

The incidence of pneumothorax due to FNAB is variable in the literature in the range of $5-45 \%{ }^{[6,25]}$ In the present study, the incidence of pneumothorax was 22.8\% [Figure 2]. While the location of the lesion, needle size, number of pleural passes and presence of cytopathologist did not show any statistical correlation with the pneumothorax rate; we noticed that the incidence of pneumothorax was significantly higher in patients where an intervening parenchyma was traversed during biopsy. Similar observations were made by Haramati and Austin ${ }^{[26]}$ and Cox et al. ${ }^{[27]}$ The pneumothorax during our study was mild-to-moderate requiring no chest tube drainage or hospitalization.

Pulmonary hemorrhage may occur with or without hemoptysis [Figure 3]. The incidence is variable in

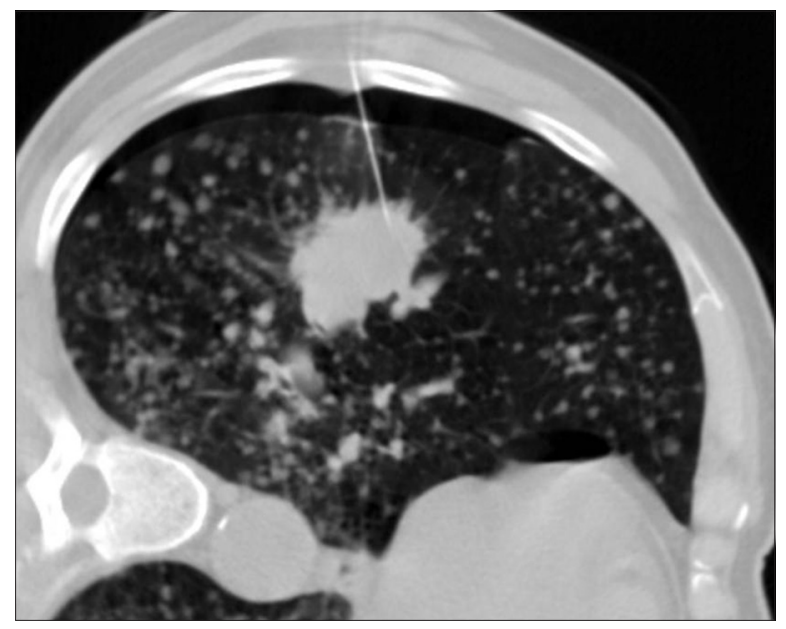

Figure 2: A 69-year-old smoker, patient placed in lateral decubitus. Mild Pneumothorax seen at non dependant portion. Cytology was adenocarcinoma literature, intrapulmonary hemorrhage is recorded in the range of $5 \%-16.9 \%$ and hemoptysis in $1.25 \%-5 \% .{ }^{[28,29]}$ In the present study, the incidence of pulmonary hemorrhage was $22.8 \%$, which was minor and asymptomatic without any hemoptysis, hypoxia, or shock.

The study had few limitations,

1. Few authors have emphasized that the angle of the needle path with respect to pleura is a novel predictor

\section{Table 8: Average number of passes versus incidence of} pneumothorax

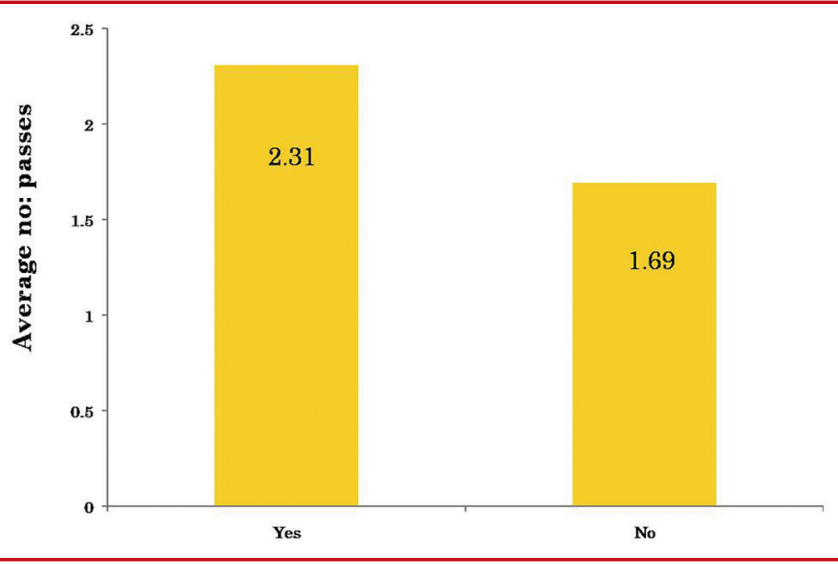

Table 9: Number of passes versus pneumothorax
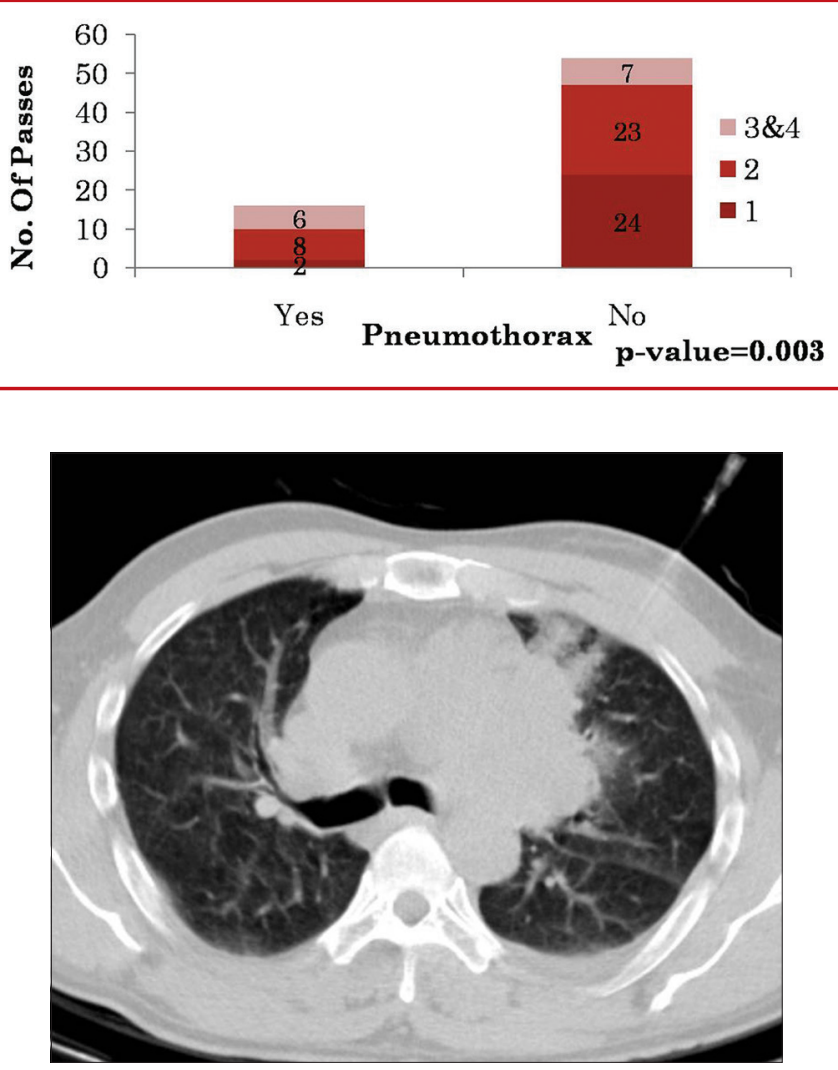

Figure 3: A 40-year-old male with Mediastinal lesion under evaluation. Pulmonary hemorrhage visible in the previous needle track site. Cytology was benign teratoma 
of pneumothorax. However, we did not look into this particular parameter in the present study

2. Radiologically, suspicious lesions with adequate cellularity were reported to be benign in the cytopathology report, and we did not repeat the FNAB procedure when there was a strong suspicion of malignancy.

CT-guided lung FNAB is a common procedure done in most radiology departments. While the procedure is simple, complications are not rare and reports of "inadequate sample" are very common and frustrating. Close attention to details of technique and collaborating "live" with a cytopathologist will go a long way in making the procedure safe and provide a high yield.

\section{Conclusion}

1. CT-guided transthoracic FNAB is an accurate method to rule out malignancy with reasonable rate of complication

2. Presence of an on-site cytopathologist significantly improves the adequacy of yield for a conclusive cytodiagnosis and should be routinely employed

3. Pneumothorax and pulmonary hemorrhage are the most common complications as a result of FNAB

4. The incidence of pneumothorax is higher when there is intervening lung parenchyma.

\section{Financial support and sponsorship}

Nil.

\section{Conflicts of interest}

There are no conflicts of interest.

\section{References}

1. Lourenço R, Camacho R, Barata MJ, Canário D, Gaspar A, Cyrne C. CT-guided percutaneous transthoracic biopsy in the evaluation of undetermined pulmonary lesions. Rev Port Pneumol 2006;12:503-24.

2. Swischuk JL, Castaneda F, Patel JC, Li R, Fraser KW, Brady TM, et al. Percutaneous transthoracic needle biopsy of the lung: Review of 612 lesions. J Vasc Interv Radiol 1998;9:347-52.

3. Ohno Y, Hatabu H, Takenaka D, Higashino T, Watanabe H, Ohbayashi $\mathrm{C}$, et al. CT-guided transthoracic needle aspiration biopsy of small $(<$ or $=20 \mathrm{~mm})$ solitary pulmonary nodules. AJR Am J Roentgenol 2003;180:1665-9.

4. Anderson JM, Murchison J, Patel D. CT-guided lung biopsy: Factors influencing diagnostic yield and complication rate. Clin Radiol 2003;58:791-7.

5. Haramati LB. CT-guided automated needle biopsy of the chest. AJR Am J Roentgenol 1995; 165:53-5.

6. Kazerooni EA, Lim FT, Mikhail A, Martinez FJ. Risk of pneumothorax in CT-guided transthoracic needle aspiration biopsy of the lung. Radiology 1996;198:371-5.

7. Stevens GM, Jackman RJ. Outpatient needle biopsy of the lung: Its safety and utility. Radiology 1984;151:301-4.

8. Saji H, Nakamura H, Tsuchida T, Tsuboi M, Kawate N, Konaka $\mathrm{C}$, et al. The incidence and the risk of pneumothorax and chest tube placement after percutaneous CT-guided lung biopsy: The angle of the needle trajectory is a novel predictor.
Chest 2002;121:1521-6.

9. Yeow KM, See LC, Lui KW, Lin MC, Tsao TC, Ng KF, et al. Risk factors for pneumothorax and bleeding after CT-guided percutaneous coaxial cutting needle biopsy of lung lesions. J Vasc Interv Radiol 2001;12:1305-12.

10. Voravud N, Shin DM, Dekmezian RH, Dimery I, Lee JS, Hong WK. Implantation metastasis of carcinoma after percutaneous fine-needle aspiration biopsy. Chest 1992;102:313-5.

11. Tarver RD, Conces DJ Jr. Interventional chest radiology. Radiol Clin North Am 1994;32:689-709.

12. Greene R, Szyfelbein WM, Isler RJ, Stark P, Janstsch H. Supplementary tissue-core histology from fine-needle transthoracic aspiration biopsy. AJR Am J Roentgenol 1985;144:787-92.

13. Stanley JH, Fish GD, Andriole JG, Gobien RP, Betsill WL, Laden SA, et al. Lung lesions: Cytologic diagnosis by fine-needle biopsy. Radiology 1987;162:389-91.

14. Khouri NF, Stitik FP, Erozan YS, Gupta PK, Kim WS, Scott WW Jr., et al. Transthoracic needle aspiration biopsy of benign and malignant lung lesions. AJR Am J Roentgenol 1985;144:281-8.

15. Li H, Boiselle PM, Shepard JO, Trotman-Dickenson B, McLoud TC. Diagnostic accuracy and safety of CT-guided percutaneous needle aspiration biopsy of the lung: Comparison of small and large pulmonary nodules. AJR Am J Roentgenol $1996 ; 167: 105-9$.

16. Westcott JL. Percutaneous transthoracic needle biopsy. Radiology 1988;169:593-601.

17. Larscheid RC, Thorpe PE, Scott WJ. Percutaneous transthoracic needle aspiration biopsy: A comprehensive review of its current role in the diagnosis and treatment of lung tumors. Chest 1998;114:704-9.

18. Miller JA, Pramanik BK, Lavenhar MA. Predicting the rates of success and complications of computed tomography-guided percutaneous core-needle biopsies of the thorax from the findings of the preprocedure chest computed tomography scan. J Thorac Imaging 1998;13:7-13.

19. Austin JH, Cohen MB. Value of having a cytopathologist present during percutaneous fine-needle aspiration biopsy of lung: Report of 55 cancer patients and metaanalysis of the literature. AJR Am J Roentgenol 1993;160:175-7.

20. Madan M, Bannur H. Evaluation of FNAC in lung diseases. Turk J Path 2010;26:1-6.

21. Mohammad GM. CT guided fine needle aspiration cytology in the diagnosis of thoracic lesions. JIMA 2001;99:1-5.

22. Stewart CJ, Stewart IS. Immediate assessment of fine needle aspiration cytology of lung. J Clin Pathol 1996;49:839-43.

23. Bandyopadhyay A, Laha R, Das TK, Sen S, Mangal S, Mitra PK. CT guided fine needle aspiration cytology of thoracic mass lesions: A prospective study of immediate cytological evaluation. Indian J Pathol Microbiol 2007;50:51-5.

24. Santambrogio L, Nosotti M, Bellaviti N, Pavoni G, Radice F, Caputo V. CT-guided fine-needle aspiration cytology of solitary pulmonary nodules: A prospective, randomized study of immediate cytologic evaluation. Chest 1997;112:423-5.

25. Saha A, Kumar K, Choudhuri MK. Computed tomography-guided fine needle aspiration cytology of thoracic mass lesions: A study of 57 cases. J Cytol 2009;26:55-9.

26. Haramati LB, Austin JH. Complications after CT-guided needle biopsy through aerated versus nonaerated lung. Radiology 1991;181:778.

27. Cox JE, Chiles C, McManus CM, Aquino SL, Choplin RH. 
Transthoracic needle aspiration biopsy: Variables that affect risk of pneumothorax. Radiology 1999;212:165-8.

28. Berquist TH, Bailey PB, Cortese DA, Miller WE. Transthoracic needle biopsy: Accuracy and complications in relation to location and type of lesion. Mayo Clin Proc 1980;55:475-81.

29. Richardson CM, Pointon KS, Manhire AR, Macfarlane JT. Percutaneous lung biopsies: A survey of UK practice based on 5444 biopsies. Br J Radiol 2002;75:731-5. 